University of Nebraska - Lincoln

DigitalCommons@University of Nebraska - Lincoln

Bureau of Sociological Research - Faculty

Publications

Bureau of Sociological Research (BOSR)

June 2005

\title{
Gender, Social Bonds, and Delinquency: A Comparison of Boys' and Girls' Models
}

\author{
Julia McQuillan \\ University of Nebraska - Lincoln, jmcquillan2@Unl.edu \\ Terceira A. Berdahl \\ University of Nebraska - Lincoln \\ Constance L. Chapple \\ University of Nebraska - Lincoln
}

Follow this and additional works at: https://digitalcommons.unl.edu/bosrfacpub

Part of the Sociology Commons

McQuillan, Julia; Berdahl, Terceira A.; and Chapple, Constance L., "Gender, Social Bonds, and Delinquency: A Comparison of Boys' and Girls' Models" (2005). Bureau of Sociological Research - Faculty Publications. 10.

https://digitalcommons.unl.edu/bosrfacpub/10

This Article is brought to you for free and open access by the Bureau of Sociological Research (BOSR) at DigitalCommons@University of Nebraska - Lincoln. It has been accepted for inclusion in Bureau of Sociological Research - Faculty Publications by an authorized administrator of DigitalCommons@University of Nebraska - Lincoln. 
Published in Social Science Research 34:2 (June 2005), pp. 357-383;

doi 10.1016/j.ssresearch.2004.04.003 Copyright (C) 2004 Elsevier Inc. Used by permission.

http://www.sciencedirect.com/science/journal/0049089X

Published online May 25, 2004.

\title{
Gender, Social Bonds, and Delinquency: A Comparison of Boys' and Girls' Models
}

\author{
Constance L. Chapple, Julia A. McQuillan, and Terceira A. Berdahl \\ Department of Sociology, University of Nebraska-Lincoln, Lincoln, NE 68588, USA \\ Corresponding author: C. L. Chapple, email cchapple2@unl.edu
}

\begin{abstract}
Past research has assessed gender differences in delinquency due to differential social controls, yet important questions remain regarding gender and social bonding. As much of this work was premised on Hirschi's measurement of the social bond, we examine whether gender moderates two parts of the social bond: the measurement of the social bond and structural differences between the social bond and delinquency. Using multiple-group structural equation modeling, we find that neither the measures of the social bond nor their relationships with property crime are gender-specific. The structural relationship between the elements of the social bond and violent delinquency differs slightly for boys and girls. We discuss implications of this research for social control theory, measuring the social bond and for gender-specific theories of social bonding and control.
\end{abstract}

\section{Introduction}

Feminist criminologists have suggested that the causal process of criminal offending differs by gender and, as such, the field of criminology has seen a growth of gender-specific theories of criminal offending (Hagan et al., 1987; Heimer and

Data for this paper are supported by NSF Grant \#367560; Michael Gottfredson and Travis Hirschi, Principal Investigators. A previous version of this paper was presented at the 2001 American Society of Criminology Meetings. 
DeCoster, 1999; McCarthy et al., 1999; Ogle et al., 1995; Steffensmeier and Allan, 1996). In particular, several authors have suggested a gendered process of social control stemming from differences in familial bonds and control (Hagan et al., 1987; McCarthy et al., 1999; Heimer and DeCoster, 1999; Ogle et al., 1995). It was suggested that girls and boys experienced different familial processes, developed different types of social bonds or were differentially controlled. Such theoretical developments are based on two lines of theory and research: feminist research on gender as structure (Risman, 1998; West and Zimmerman, 1987) and Hirschi's social bonding theory (Hirschi, 1969). Researchers are increasingly suggesting that gender as structure is created, maintained, and differentially experienced within families leading to gender differences in boys' and girls' delinquency.

Underscoring this line of theoretical development is the assumption that social controls operate differently or have differential importance for boys and girls, thus necessitating gender-specific theories of social control. For example, Hagan et al.'s power-control theory suggests that Marxist-patriarchal arrangements within the family translate into differential control and social bonds for boys and girls. Whereas, Heimer and DeCoster's (1999) gendered theory of violent delinquency suggests that girls' relational socialization and gendered social bonds impact their involvement in violence (see also, Steffensmeier and Allan, 1996). Much of the argument concerning gender differences in relational control rests squarely in a gendered "ethic of care" (Gilligan, 1982; Mears et al., 1998; Steffensmeier and Allan, 1996), which implies a gendered process of affective bonding. The assumption of gendered social bonding is not entirely in keeping with Hirschi's version of the social bond in which he suggests that social controls are gender neutral. Yet his proposition that boys and girls bond similarly to conventional others has never been tested.

If gender moderates how the social bond is measured, then models using a "general" social control model for male and female offending would be mis-specified. More importantly, previous findings of gender differences in social bonding may have incorrectly attributed differences in bonding to structural, rather than measurement, differences. Two critical measurement and modeling questions remain concerning gender, social control, and social bonding. First, does gender moderate the measurement of social bonds? Second, does gender moderate the structural relationship between the social bond and delinquency for boys and girls? Before we address these two research questions, we review the relevant literature on gender, social bonds, and social control.

\section{Literature review}

\subsection{Hirschi's social control theory}

Hirschi, in Causes of Delinquency (1969), suggests that youths' bonds to conventional society deter their involvement in deviant activities. According to Hirschi, the more strongly bonded an individual is to conventional society, the more 
sensitive he or she is to the loss of approval from conventional others. Hirschi suggests that the social bond contains four elements: attachment, involvement, commitment, and belief. Attachment is the affective identification an individual has with parents, teachers, and peers. High levels of attachment to conventional, or law-abiding others, deters deviation as highly attached people do not want to risk losing the love and respect of people close to them. Involvement represents the time one spends in conventional activities. Hirschi acknowledges that crime can take just minutes to commit; he suggests that involvement in conventional activities alone is insufficient to deter deviation. Commitment to conventional lives and activities is the third component of the social bond. Hirschi suggests that youths who are committed to hard work and achievement are less likely to deviate. The fourth dimension, belief, measures one's support of general social norms and public laws. Hirschi considered each of these elements of the social bond to be unique yet related variables comprised of multiple indicators. Therefore, the elements of the social bond can be measured using multiple indicator latent variables that are allowed to correlate.

\subsection{Research on gender differences in relational and instrumental control}

Gilligan, in A Different Voice (1982), suggested that women are socialized to be more relational and focused on the cares and feelings of others than men. Criminologists have acknowledged this idea of gendered relational control and have suggested that socialization, although part of patriarchal institutional arrangements, may protect girls from engaging in delinquency, particularly violent delinquency (Heimer and DeCoster, 1999; Mears et al., 1998; Steffensmeier and Allan, 1996). Such research implies a gender differentiated process of social bonding, in which girls have a greater capacity for relational and affective bonding, different types of relational bonding, and that these bonds exert differential control on girls' delinquency. Other research suggests an alternate gendered process of control, instrumental control, leading to girls' lower rate of delinquency (Hagan et al., 1987). While Hagan et al.'s research focuses on the importance of gender differences in supervision and monitoring, they also suggest that girls and boys differ in their "preference for risk" which is acquired, through gender differences in affective bonding. Suggesting that girls from patriarchal households have a lower preference for risk because they have been successfully socialized to passive gender roles which place a premium on affective, or relational, bonding. Taken together, this research implies that important gender interactions in the measurement of social bonding and the structural relationship between social bonding and delinquency exist and should be evaluated. To date, a host of research has attended to the second suggestion, gender differences in the structural relationship between the social bond and delinquency, but gender differences in the measurement of social bonding have not been assessed. Because a wealth of information exists on gender and the structural relationship between social bonding and delinquency, we review this literature first but suggest that as measurement differences in social bonding have not been assessed, many of these findings may be premature. 


\subsection{Research on gender, social bonds, and offending}

As Kempf (1993) suggests, cross-study comparability of research on social control theory is hampered by incomplete specifications of the theory and differential measurement of the social bond. This critique is particularly true of the research on gender and social bonding. All of the studies we uncovered on gender, social bonds, and delinquency evaluated differences in the structural relationship between the social bond and delinquency for males and females; none of the previous literature evaluated gender invariance in the measurement of the social bond. Past studies on gender and social bonds that did not test for gender differences in the measurement of the social bond, may have erroneously attributed gender invariance or gender differences in social control to the structural relationship between the social bond and criminal offending rather than possible measurement differences in the social bond. Our paper is designed to rectify this oversight.

Past research has focused on whether gender differentially impacts the effect of the social bond on delinquency. Generally, most of the research, with the few notable exceptions listed below, suggests that social bonds operate similarly to deter delinquency for boys and girls. In terms of the explanatory power of social bonding by gender, Friedman and Rosenbaum (1988) and Alarid et al. (2000) found that social bond variables similarly explained boys' and girls' delinquency. Along the same line, Jensen and Eve (1976) found that the social bond variables used to explain boys' and girls' delinquency were similar. In regard to the similarity of the effect of the family on boys' and girls' delinquency, Canter (1982) suggested that the nature and degree of family bonds were similar for boys and girls. Finally, the generality of the relationship between social bonds was confirmed by two studies. Liu and Kaplan (1999) and Smith and Paternoster (1987) regarded social control theory to be general enough to adequately explain both male and female offending.

Past research has also suggested that gender moderates the relationship between the social bond and delinquency. The two studies that tested for interaction effects between the elements of the social bond and gender on delinquency had mixed results. Friedman and Rosenbaum (1988) found that their measure of commitment, consistently doing homework, had a greater negative effect of delinquency for girls than boys; they found no gender difference in parental attachment, measured as "getting along with parents," and delinquency. Alternately, Seydlitz (1991) found in her three way interactions between age, gender, and the social bond, that parental attachment, measured by "the need to obey parents' rules," was moderated by gender and had a greater effect for 13- to 14-year-old boys and 15- to 16-year-old girls in deterring their substance use. Also, "consideration for parents," which could measure parental attachment, was a better deterrent of 15- to 18-year-old girls' substance use than for boys of the same age.

Other research highlights the differential impact of the social bond for male and female offending. These are the notable exceptions to the similarity findings explained earlier. These findings of gender differences in the effects of the social bond on delinquency in conjunction with gender research on differential social bonding of girls and women in general, has aided the development of theories of gendered 
social bonding in delinquency research. For example, several researchers found that models incorporating measures of social bonds fit better for boys' delinquency (Canter, 1982; Cernkovich and Giordano, 1987; Hindelang, 1973) while others found that their social bonding models better predicted girls' delinquency (Alarid et al., 2000; Friedman and Rosenbaum, 1988; Gove and Crutchfield, 1982). Alarid et al. (2000) found that parental attachment was the only element of the social bond that was a stronger predictor of women's felony offending. Huebner and Betts (2002) echo this finding in their recent analysis of the social bond and youth development in which their measure of conventional involvement explains boys' delinquency better than girls'. Finally, although Friedman and Rosenbaum (1988) concluded that social control theory worked similarly for male and female offending, they found that school commitment was a stronger predictor of female than male delinquency.

Such contradictory findings regarding gender invariance in the effect of the social bond on delinquency lead to confusion regarding whether gender-specific theories of social control are necessary. It is difficult to know if the inconsistencies in gender invariance across studies come from measurement problems, gendered measurement differences or gendered structural differences between the social bond and delinquency. These disparate findings are likely the result of two things: misspecification of the social control model and/or gender differences in the measurement of the social bond. If gender differences in the measurement of the social bond exist but are not assessed, then measurement error attenuates relationships between the social bond and delinquency, making significant effects more difficult to achieve. Alternately, studies finding gender similarity, such as Friedman and Rosenbaum's (1988) and Jensen and Eve's (1976) or studies finding gender differences such as Cernkovich and Giordano's (1987) and Canter's (1982) may have incorrectly attributed similarity (or difference) to the effects of the social bond on delinquency, rather than similarity (or difference) in the measurement and meaning of the social bond for boys and girls. We suggest that to help brook this debate, gender invariance in social bonding must be assessed to better inform research on gendered social bonding and delinquency. Additionally, a growing theoretical trend has emerged which suggests that girls commit less crime than boys because they are differentially bonded or controlled. Much of this literature suggests a gendered process of bonding in which girls and boys develop different types and levels of social bonds, yet the key question regarding whether girls and boys do actually bond differently to conventional others has never been evaluated. Our goal is to address the limitations of previous research on gender and social bonding and to inform theories of gendered social bonding by evaluating the moderating effect of gender on the measurement of social bonds and assessing gender invariance in the structural relationships between the social bond and delinquency.

\section{Methods}

We specify a model that measures all of the elements of the social bond as latent variables with multiple indicators and uses data from young men and 
women, offenders, and non-offenders, in their prime ages for offending. We use multiple-groups structural equation modeling (SEM) to evaluate the equivalence of the loadings in the measurement model and the equivalence of the path coefficients in the structural model across gender groups. This approach provides ways to determine if differences exist between boys and girls, and if they do, where they are. We model all four elements of the social bond, appropriately measured as latent variables (see Costello and Vowell, 1999; Matsueda, 1982 for measurement of social control theory with latent variables). First, we evaluate gender differences in the measurement of social bonds by comparing increasingly constrained measurement models: (a) lambda equal, (b) lambda and tau equal, (c) lambda, tau, and psi equal. Second, we evaluate the structural relationships between the elements of the social bond and delinquency across gender groups by comparing the structural models with paths (gamma) not constrained to be equal between girls and boys with one that constrains the structural paths to be equal. If the structural paths are not significantly different for boys and girls, we have evidence that the theory as a whole is not gender-specific.

\subsection{The sample}

Data for this study were collected in the spring of 1997 in "Collegeville," a medium sized, suburban/rural city that houses a major southern university. Students in Collegeville's two public school districts in grades 9 through 11 present on the day of data collection were included in the sample. ${ }^{1}$ The students present were asked to complete a 200 question self-report survey. Members from the project research staff or teachers trained by the project staff in survey administration were present during data collection. Given policies in this school district at the time of data collection, only passive consent from the participating parents was required to survey minor children.

Parents were notified by the school district of the upcoming survey and were told to notify the school district if they did not want their children to participate. Parents not wishing their children to be involved in the survey were given the right to refuse participation. We received no word from the school district that any parent, once informed of the study, disallowed their child's participation. We assured the students of anonymity and confidentiality and we advised participants to refrain from answering any questions that made them feel uncomfortable or to refrain from data collection completely. No students refused to fill out the survey although approximately 3\% of surveys (approximately 25 surveys)

\footnotetext{
${ }^{1}$ The school district's name has been changed to protect the students' confidentiality. According to available data from the Collegeville School District attendance for the school district in 1997 was 94.5\%; the drop-out rate for Collegeville East and West High Schools is .7 and 17.8\%, respectively. Unfortunately, grade-, school-, and sex-specific attendance information is not available; nor was sex-specific drop-out information available. In terms of gender differences in dropping-out of school on a national level, according to US Department of Labor, Bureau of Labor Statistics data in 1997, girls were less likely to drop-out of school than boys. Finally, we did not find any significant gender difference in girls' and boys' truancy, measured as "staying away from school because you had something better to do," for the students in our sample.
} 
contained such incomplete data that they were unusable. Collegeville has two public high schools and two public junior high schools. One district serves mostly middle and upper class families and the other serves mostly working class families in Collegeville. ${ }^{2}$

The resulting survey instrument contains data on delinquency, victimization, and etiological variables thought to influence crime for 1139 junior high and high school students. An aim of this data collection effort was a replication of Hirschi's Richmond Youth Survey used in Causes of Delinquency (1969) and to collect data tenable for evaluation of control theory. This is a self-report sample that encompasses the majority of all enrolled students in grades 9 through 11 in Collegeville in the spring of 1997. According to spring 1997 enrollment figures provided by the Collegeville school district, our sample contains $69 \%$ of 9 th graders, $62 \%$ of 10th graders, and 58\% of 11th graders enrolled in Collegeville's public school system. The sample is similar to the demographics of Collegeville's youth as a whole. ${ }^{3}$ Our sample is slightly older and contains slightly more non-white youths than the general Collegeville youth population in 1997.

A study of high school students is useful as it captures potential offenders in their prime years of offending. High school samples, although certainly not as criminal as incarcerated samples (particularly with respect to serious delinquency - see Cernkovich et al., 1985), report significant levels of involvement in various criminal activities (Hindelang et al., 1981). We have clearly missed many serious offenders who were not enrolled in school, or if enrolled, were unlikely to be present, yet we have also captured a number of students who report high levels of delinquency and involvement in serious crimes. ${ }^{4}$ Although this is not a representative sample of high school students, our focus is not on generalizing to the population, but on comparing boys and girls within the sample. More importantly, we know of no other longitudinal or nationally representative data set that contained the breadth and depth of measures of all of the elements of the social bond provided in this data set. Because our critical analyses center on the measurement of the social bond as originally set forward by Hirschi (1969), we believed our data set was unique in

$247.7 \%$ of the students in Collegeville West High School reported that their parents earned less than $\$ 25,000$ per year, whereas $55.7 \%$ of students in Collegeville East High School reported that their parents earned $\$ 40,000$ or more per year. The distributions for the respective junior high schools are similar.

${ }^{3}$ Compared to the Collegeville city population, our respondents are more likely to be ages 15 and 16. The sample and the population are similarly distributed in terms of sex. In terms of race, our sample is slightly more representative of minority students than the population of Collegeville itself. Collegeville's population of 14- to 17-year-olds are $90 \%$ white, $4.7 \%$ black, 1.5\% Native American, $1.3 \%$ Asian, and $5.4 \%$ Hispanic. Our sample is $86.4 \%$ white, $5.2 \%$ black, $2.7 \%$ Native American, $2.2 \%$ Asian, and 3.5\% Hispanic. Overall, our sample has more blacks, Native Americans, and Asians, but fewer Hispanics than the Collegeville population.

${ }^{4}$ Forty-six percent of our sample report at least one act of "Used force to get something you wanted from another person," and 5.5\% report having done it "many times." Forty-two percent have "Beaten up on someone (not a brother or sister) or hurt anyone on purpose" at least once, and 5.9\% report having done it "many times." Twenty-five percent of the sample has been picked up by the police and 3.2\% report being picked up "many times." 
its content which outweighed it cross-sectional character. Our analyses and conclusions are not causal but rather, suggestive of patterns or trends in the data that could be verified with longitudinal data when available.

Slightly over half of the study participants are girls (51\%), most are Baptist (24\%) or belong to another Protestant church (23.7\%), and most are white $(86 \%)$. The majority of the students are 16 years old or younger $(75 \%)$ and in 9 th or 10 th grade $(70 \%)$. Family incomes are almost split into quarters between less than $\$ 25,000, \$ 26-39,000, \$ 40-65,000$, and more than $\$ 66,000$. Almost one-fifth of the students come from families that are current or past welfare recipients $(17 \%)$. Most live in homes with their "real" father (63\%) or "real" mother (86\%), although residing with the mother is more common. Almost half report fathers (84\%) and mothers $(43.9 \%)$ with college degrees. The majority of fathers are employed fulltime $(84 \%)$, and about two-thirds of the mothers are employed full-time (64\%).

Nine percent of the cases are missing values on one of the variables in the analysis. An additional $4 \%$ are missing information on more than one variable. Because of missing data and the moderate sample size, we used full information maximum likelihood (FIML) analysis in the AMOS program. Simulation studies suggest that FIML produces less bias than many currently available ways to handle missing data (Worthke, 1998).

\subsection{Measures}

Hirschi (1969) describes four elements of the social bond: attachment, commitment, involvement, and belief. As Hirschi specifies three locations for conventional attachment (attachment to parents, school, and peers) it is possible to accurately model Hirschi's social bond with at least six bonds (parent, peer and school attachment, commitment, involvement, and belief). We initially modeled each one of Hirschi's elements of the social bond: school attachment, parental attachment, peer attachment, school commitment, involvement in conventional activities, and belief in conventional laws and morals. School attachment and school commitment were highly collinear and because most researchers place primacy on the importance of parental attachment and school commitment on deterring delinquency, we dropped school attachment from the model and retained parental attachment, peer attachment, school commitment, involvement, and belief.

Other researchers (Costello and Vowell, 1999) modeled the social bond as a second-order factor model with the four elements of the social bond (attachment, commitment, involvement, and belief) modeled as separate, latent variables which then comprise a second-order latent variable, the social bond. We considered this route-especially given the similarity of our data to theirs (Costello and Vowell used Richmond Youth Survey data and we use data that are almost an exact replication). In the end, we chose not to use a second-order factor model for two reasons. First, the measurement diversity present in the field of research on gender and social bonds has created confusion regarding the gender invariance in the social bond and delinquency relationship. Second, by modeling each element of the social bond, we are able to assess gender invariance in the measurement of the indi- 
vidual elements (and each indicator of each element of the social bond) of the social bond and in the structural relationships between these elements and delinquency.

The six latent social bond variables we created (confirmatory factor analysis indicated that "attachment" was measured with two parental attachment variables and one peer attachment variable), with the items measuring each latent variable, are listed in Table 1. Involvement in organizations and peer attachment have the smallest Cronbach's $a^{\prime}$ 's of inter-item reliability (involvement $=.53$ for girls and .46 for boys, peer attachment $=.47$ for girls and .48 for boys $)^{5}$, the reliability for the other four latent variables is higher (ranging from .63 to .80). We have multiple indicators for each of the latent constructs of the social bonds: peer attachment, parental attachment, commitment to education, involvement in organizations, and beliefs about the legal system. ${ }^{6}$

Seydlitz (1993) and Steffensmeier and Allan (1996) suggest that the efficacy of social bonds for explaining girls' delinquency depends upon the type of delinquency studied (e.g., property, violent crime; serious or non-serious crime). Therefore, we selected two measures of delinquency for this study, violent crime, and theft. Violent crime consists of three observed measures (see Table 1 for a description of these items). Each of the three measures captures a slightly different aspect of interpersonal violence. We created a single latent variable with these three items ("violent crime"). The three variables measuring theft (see Table 1 for a description of these items) are actually different versions of the same variable with increasing dollar amounts ("Have you ever stolen an item worth less than \$5 / \$5-\$50 / more than \$50?"). It makes sense to combine the three individual measures of theft into one observed variable that measures the frequency and seriousness of theft. Responses were coded to indicate a range of behavior from no involvement in theft, little involvement in small theft, frequent involvement in small theft, infrequent involvement in large theft, and frequent involvement in large theft. The resulting variable contains 64 categories of responses ranging in seriousness and frequency with involvement in serious theft, even occasionally, adding to a higher score than involvement in less serious theft. The composite theft variable is highly skewed (about one-third of the sample never stole anything), therefore we logged it to more closely approximate a normal distribution.

\footnotetext{
${ }^{5}$ We understand that our measures of peer attachment and involvement in conventional activities do not have high internal consistency and may not be measuring what they purport to measure. However, given that the aim of this paper is to test for gender interactions in the measurement of social control theory as it was originally measured, we retain the measurement of peer attachment and involvement in conventional activities as Hirschi originally suggested.

${ }^{6}$ The latent variables in this model have good convergent validity (see the loadings in Table 2) and good discriminant validity (see the correlations among the latent variables in Table 3). Despite the empirical and conceptual separateness of the latent variables, we anticipated that we would need to correlate the errors for some of the observed indicators because of likely measurement effects from pencil and paper surveys. We used modification indices in the AMOS 4.0 software (on the data restricted to cases with no missing values) to determine which errors had the highest correlations. We then had 21 correlated errors of the observed indicator variables (see Appendix B). All of these correlated errors are reasonable given the suggestions of the theory. As MaCallum et al. (1992) make clear, this modified model now has a better fit to this sample but may not be generalizable to other samples or to the population.
} 
Table 1. Means and variances for the observed variables: comparing girls and boys

\begin{tabular}{lcc}
\hline Item description $^{\mathrm{a}}$ & Girls $(N=577)$ & Boys $(N=555)$ \\
& Mean Variance & Mean Variance \\
\hline
\end{tabular}

Theft

Have you ever...

Taken things of larger value $(>\$ 50)$ that did not belong to you? ${ }^{\mathrm{A}}$

$\begin{array}{rrrr}1.17 & .33 & 1.39^{* *} & .74 \\ & & & \\ 1.42 & .59 & 1.65^{* *} & .91 \\ 1.72 & .74 & 2.12^{* *} & 1.01 \\ 0.19 & 1.27 & 0.66^{* *} & 1.82\end{array}$

Violent crime ( $\alpha=.75$ for girls, .73 for boys)

Have you ever...

Slapped, shoved or hit another student at school? A

Used force to get something you wanted from another person? ${ }^{\mathrm{A}}$

$\begin{array}{llll}1.56 & .71 & 2.11^{* *} & 1.08 \\ 1.48 & .61 & 1.87^{* *} & .89 \\ 1.41 & .55 & 1.85^{* *} & .89\end{array}$

Peer attachment ( $\alpha=.47$ for girls, .48 for boys)

I respect my best friends* opinions about the important things in life. ${ }^{\mathrm{D}}$

I would like to be the kind of person my best friend is. ${ }^{\mathrm{D}}$

Depend on parents ( $\alpha=.63$ for girls, .64 for boys)

Would your mother stick by you if you got into really bad trouble? ${ }^{\mathrm{E}}$

$\begin{array}{llll}4.16 & 1.29 & 4.13 & 1.21\end{array}$

Would your father stick by you if you got into really bad trouble? ${ }^{\mathrm{E}}$

$\begin{array}{llll}3.83 & 1.75 & 3.83 & 1.60\end{array}$

Parental attachment ( $\alpha=.80$ for girls, .76 for boys)

I talk over future plans with my parents ${ }^{\mathrm{D}}$

I would like to be the kind of person my mother is $D$

I share my thoughts and feelings with my mother ${ }^{\mathrm{D}}$

My mother seems to understand $\mathrm{me}^{\mathrm{D}}$

$\begin{array}{llll}3.80^{*} & 1.26 & 3.56 & 1.34 \\ 3.00 & 1.66 & 2.97 & 1.50 \\ 3.41^{* *} & 1.77 & 3.04 & 1.64 \\ 3.18 & 1.83 & 3.34^{*} & 1.64\end{array}$

Commitment to education ( $\alpha=.66$ for girls, .67 for boys $)$

I usually finish my homework ${ }^{\mathrm{D}}$

I try hard in school ${ }^{\mathrm{D}}$

What kind of grades do you get?' (reversed)

$\begin{array}{llll}3.51^{*} & 1.35 & 3.29 & 1.54\end{array}$

$\begin{array}{llll}4.11^{* *} & .80 & 3.71 & 1.11\end{array}$

$\begin{array}{llll}4.16^{* *} & .79 & 3.85 & .93\end{array}$

Involvement in organizations ( $\alpha=.53$ for girls, .46 for boys) Have you ever played on an organized sports team? ${ }^{\mathrm{A}}$ On average, how often do you attend religious services? ${ }^{C}$ Have you ever participated in youth clubs outside of school? ${ }^{\mathrm{A}}$

$\begin{array}{llll}2.77 & 1.44 & 3.16^{* *} & 1.17 \\ 3.45^{*} & 2.68 & 3.21 & 2.69 \\ & & & \\ 2.50 & 1.44 & 2.48 & 1.34\end{array}$

\footnotetext{
${ }^{a}$ Response categories are listed as follows:

A. (1) Never (2) Once or Twice (3) Several times (4) Many times.

B. (1) Mostly A*s (2) Mostly B*s (3) Mostly C*s (4) Mostly D*s (5) Mostly F*s.

C. (1) Once a week or more (2) two or three times a month (3) Once a month (4) a few times a year (5) never or almost never.

D. (1) Strongly agree (2) agree (3) undecided (4) disagree (5) strongly disagree.

E. (1) Certainly (2) Probably (3) Maybe (4) I doubt it (5) I don't know.
} 
Table 1 (continued)

\begin{tabular}{|c|c|c|c|c|}
\hline \multirow[t]{2}{*}{ Item description $^{\mathrm{a}}$} & \multicolumn{2}{|c|}{ Girls $(N=577)$} & \multicolumn{2}{|c|}{ Boys $(N=555)$} \\
\hline & Mean & Variance & Mean & Variance \\
\hline \multicolumn{5}{|c|}{ Belief in the legal system ( $\alpha=.74$ for girls, .69 for boys) } \\
\hline $\begin{array}{l}\text { Most things people call delinquency don }{ }^{*} \mathrm{t} \text { re } \\
\text { hurt anyone }^{\mathrm{D}} \text { (Reversed) }\end{array}$ & $3.27^{* *}$ & .94 & 3.03 & 1.08 \\
\hline I have lots of respect for the police $\mathrm{e}^{\mathrm{D}}$ & 3.22 & 1.59 & 3.10 & 1.80 \\
\hline Rules were made to be broken ${ }^{\mathrm{D}}$ (Reversed) & $3.44^{*}$ & 1.66 & 3.18 & 1.73 \\
\hline $\begin{array}{l}\text { It }^{*} \mathrm{~s} \text { okay to get around the law if you can get } \\
\text { away with it } \mathrm{t}^{\mathrm{D}} \text { (Reversed) }\end{array}$ & $3.57^{* *}$ & 1.66 & 3.17 & 1.70 \\
\hline
\end{tabular}

The data we use are cross-sectional, therefore we are unable to meet one of the basic requirements for causal ordering of variables, temporal priority. However, Hirschi has suggested in other work (Gottfredson and Hirschi, 1990) that parental attachment, commitment to education, and belief in morality are temporally prior to delinquency for most children. We use the clear theoretical framework provided by social control theory to create the model presented here (see Figure 1 and Figure 2). Each of the social bond measures and the resulting latent variables are conceptualized as having a direct negative relationship with violence and theft. Our findings do not imply causal relationships, as other research indicates the reflexive nature of social bonds and delinquency (Agnew, 1991; Liska and Reed, 1985), but are associative and worthy of further longitudinal research.

\subsection{Analytic strategy}

We designed our analytic strategy to address two concerns: are social bonds moderated by gender either in the measurement of latent constructs or in the structural paths leading from the elements of the social bond to theft and violent crime? Castro et al. (1987) demonstrate that when measures in the measurement model differ between groups, differences in structural parameters cannot be adequately interpreted. Errors in measurement can also lead to the attenuation of structural paths. Therefore, if measurement error differs for boys and girls but is unaccounted for, the difference can appear as differences in structural paths where none actually exist. Similar to Arneklev et al.'s (1999) analysis of the measurement invariance of Gottfredson and Hirschi's (1990) concept of self-control, we use a hierarchy of invariance approach to test the equality between boy's and girl's measurement models and structural paths (Bollen, 1989). According to Jaccard and Choi (1996), a necessary first step in the analysis of the invariance of the social bond is to assess the overall fit of our social bond measurement model. If 
the initial, unconstrained models (allowing for gender differences) have a poor fit to the data, then adding constraints will make the models worse. Therefore we first need to establish a well-fitting unconstrained model.

To answer our main research questions regarding the gender interactions in measuring social bonds, we first constrain parameters of the measurement model to be equal between boys and girls, and compare the fit of the constrained and the unconstrained models. According to Byrne and Campbell (1999) and Raju et al. (2002), if the model fit is not significantly worse when the factor loadings (LXs and LYs) are constrained to be equal, then the measurement models are "the same." We also show the results of adding equality constraints for the error variances and the latent variable co-variances following Bollen (1989). If the fit of the model becomes significantly worse when each set of parameters are constrained to be equal, then that part of the model does not fit the same for boys and girls. We assess the fit of the models using standard measures of model fit available for structural equation models in AMOS 4 (Arbuckle and Wothke, 1999). ${ }^{7}$

What does it mean to say that the measurement models are the same for boys and girls? Does this mean that all parameters for both groups must not differ significantly? Both Byrne (1988) and Reise et al. (1993) argue that this criterion is too stringent due to sample-specific artifacts that may influence item variances and co-variances. Following Gottfredson and Koper (1997) and Raju et al. (2002), we define measurement invariance as invariance in the factor loadings (the scale units relating each item to its latent underlying construct - the $\lambda$ coefficients) across samples. In the measurement model we provide tests of invariance for co-variances and error variances but focus on the factor loadings as the parameters of greatest interest. Once gender invariance or difference in the measurement of the social bond is assessed in the measurement model, the six covariances between delinquency and the elements of the social bond are then redrawn as structural paths in the structural model. To test the gender invariance of these structural paths, we begin with a model with equal factor loadings (per results from the measurement model described next), and then constrain these six structural paths to be equal (Model 5 in Table 4). We also add constraints on the co-variances among the elements of the social bond, although this is a more stringent test than the theory implies (Model 6 of Table 4).

\footnotetext{
${ }^{7}$ Kline (1998), Hayduk (1987), Hoelter (1983), and Browne and Cudeck (1992) recommend using several indices of fit, since no model will perfectly fit the data, and each measure has limitations We use the following fit statistics: (a) the $\chi^{2}$ (with $d f$ and $p$ value for significance), (b) $\chi^{2} / d f$ ratio (c) the normed fit index (NFI), (d) the parsimony normed fit index (PNFI) is the NFI adjusted to penalize for a lack of parsimony, (e) the root mean square error of approximation (RMSEA) indicates the average lack of fit per degree of freedom. We also use PCLOSE to test the null hypothesis that RMSEA is no greater than .05 (Browne and Cudeck, 1992) (f) the Akaike Information Criterion (AIC) provides a way to compare non-nested models (the lowest number indicates the best fit), (g) the expected cross-validation index (ECVI) is useful for comparing non-nested models reflecting the discrepancy between model-implied and observed co-variance matrices and finally, to compare the difference between models, we use the $\chi^{2}$ goodness-of-fit (the lowest number indicates the best fit).
} 


\section{Results}

Table 1 provides all of the items comprising each latent variable, with means and standard deviations by gender. Girls have significantly higher average social bond scores on many of the items. Girls are significantly more likely to "respect my best friends' opinions," "want to be the kind of person my best friend is," "talk over future plans with my parents," and "share thoughts and feelings with my mother." Girls are more likely to agree that they "usually finish all of their homework," "try hard in school," get higher grades, and regularly attend religious services. Surprisingly, girls are also more likely to agree with items that indicate lower levels of conventional belief such as "most things people call delinquency don't really hurt anyone" and "its okay to get around the law if you can get away with it." Boys, conversely, are significantly more likely to agree that "my mother seems to understand me" and that they have more experience playing on organized sports teams. Boys also have significantly higher involvement in each type of theft and violence surveyed.

Average differences between boys and girls, particularly higher average delinquency, should not necessarily lead to differences in the relationships among the elements of the social bond. If Hirschi (1969) is correct, then the manner in which the elements of the social bond relate to delinquency should be the same for boys and girls, regardless of the different mean levels between groups. Greater bonds should be associated with lower delinquency regardless of gender. Before directly addressing the structural relationships among the latent variables, we first assess the measurement model.

\subsection{Does gender moderate the measurement of social bonds?}

We analyzed the co-variance matrices for the observed items by gender (we present the correlation matrix in Appendix A). We found patterns of convergent and discriminant validity in our measures that are consistent with the theory as the items suggested to measure one element of the social bond correlate more highly with each other than with items measuring other elements of the social bond (i.e., ... the items measuring school commitment correlate more highly with each other than with items measuring belief). Table 2 provides the unrestricted measurement model regression loadings by gender. Standardized measurement loadings range from .38 to .95 , with the majority over .60 , indicating good convergent validity.

Table 3 provides bi-variate correlations among the latent social bond variables and the dependent variables. These correlations indicate overall good discriminant validity, because most of the correlations are below .60. The only exception is the strong correlation between attachment to parents and depending upon parents for girls $(r=.65)$. As expected, all but one of the elements of the social bond had large negative, significant bi-variate correlations with the delinquency measures. Peer attachment is unrelated to either theft or violent delinquency for the girls in our sample. As theorized, each of the latent variables measuring the elements of the social bond had positive correlations with each other. 
Table 2. Baseline measurement model comparing boys and girls regression loadings (LY and LX)

\begin{tabular}{|c|c|c|c|c|}
\hline & \multicolumn{2}{|l|}{ Boys } & \multicolumn{2}{|l|}{ Girls } \\
\hline & $\begin{array}{l}\text { Factor } \\
\text { loadings }\end{array}$ & $\begin{array}{l}\text { (Standard- } \\
\text { ized) }\end{array}$ & $\begin{array}{l}\text { Factor } \\
\text { loadings }\end{array}$ & $\begin{array}{l}\text { (Standard- } \\
\text { ized) }\end{array}$ \\
\hline \multicolumn{5}{|l|}{ Theft } \\
\hline $\begin{array}{l}\text { Directly observed measure combining the } \\
\text { three theft items, logged }\end{array}$ & 1.00 & & 1.00 & \\
\hline \multicolumn{5}{|l|}{ Violent crime } \\
\hline $\begin{array}{l}\text { Have you ever slapped, shoved or hit } \\
\text { another student at school? }\end{array}$ & 1.03 & $(0.72)$ & 0.99 & $(0.71)$ \\
\hline $\begin{array}{l}\text { Have you ever used force to get something } \\
\text { you wanted from another person? }\end{array}$ & 0.83 & $(0.63)$ & 0.82 & $(0.63)$ \\
\hline $\begin{array}{l}\text { Have you ever beaten up on someone or } \\
\text { hurt anyone on purpose? }\end{array}$ & 1.00 & $(0.74)$ & 1.00 & $(0.79)$ \\
\hline \multicolumn{5}{|l|}{ Peer attachment } \\
\hline $\begin{array}{l}\text { I respect my best friends' opinions about the } \\
\text { important things in life }\end{array}$ & 1.09 & $(0.63)$ & 0.53 & $(0.48)$ \\
\hline $\begin{array}{l}\text { I would like to be the kind of person my best } \\
\text { friend is }\end{array}$ & 1.00 & $(0.50)$ & 1.00 & $(0.68)$ \\
\hline \multicolumn{5}{|l|}{ Depend on parents } \\
\hline $\begin{array}{l}\text { Would your mother stick by you if you } \\
\text { got into really bad trouble? }\end{array}$ & 1.00 & $(0.66)$ & 1.00 & $(0.68)$ \\
\hline $\begin{array}{l}\text { Would your father stick by you if you } \\
\text { got into really bad trouble? }\end{array}$ & 1.28 & $(0.77)$ & 1.14 & $(0.71)$ \\
\hline \multicolumn{5}{|l|}{ Parental attachment } \\
\hline I talk over future plans with my parents & 1.00 & $(0.60)$ & 1.00 & $(0.57)$ \\
\hline $\begin{array}{l}\text { I would like to be the kind of person my } \\
\text { mother is }\end{array}$ & 1.03 & $(0.59)$ & 1.36 & $(0.67)$ \\
\hline $\begin{array}{l}\text { I share my thoughts and feelings with } \\
\text { my mother }\end{array}$ & 1.21 & $(0.66)$ & 1.62 & $(0.78)$ \\
\hline My mother seems to understand me & 1.51 & $(0.82)$ & 1.87 & $(0.88)$ \\
\hline \multicolumn{5}{|l|}{ Commitment to education } \\
\hline I usually finish my homework & 1.00 & $(0.70)$ & 1.00 & $(0.72)$ \\
\hline I try hard in school & 0.78 & $(0.64)$ & 0.69 & $(0.65)$ \\
\hline What kind of grades do you get? & 0.80 & $(0.72)$ & 0.64 & $(0.61)$ \\
\hline \multicolumn{5}{|l|}{ Involvement in organizations } \\
\hline $\begin{array}{l}\text { Have you ever played on an organized } \\
\text { sports team? }\end{array}$ & 1.00 & $(0.47)$ & 1.00 & $(0.44)$ \\
\hline $\begin{array}{l}\text { On average, how often do you attend religious } \\
\text { services? }\end{array}$ & 1.48 & $(0.45)$ & 1.41 & $(0.95)$ \\
\hline $\begin{array}{l}\text { Have you ever participated in youth clubs } \\
\text { outside of school? }\end{array}$ & 1.11 & $(0.50)$ & 1.63 & $(0.76)$ \\
\hline
\end{tabular}


Table 2 (continued)

\begin{tabular}{|c|c|c|c|c|}
\hline & \multicolumn{2}{|l|}{ Boys } & \multicolumn{2}{|l|}{ Girls } \\
\hline & $\begin{array}{l}\text { Factor } \\
\text { loadings }\end{array}$ & $\begin{array}{c}\text { (Standard- } \\
\text { ized) }\end{array}$ & $\begin{array}{l}\text { Factor } \\
\text { loadings }\end{array}$ & $\begin{array}{c}\text { (Standard- } \\
\text { ized) }\end{array}$ \\
\hline \multicolumn{5}{|l|}{ Belief in the legal system } \\
\hline $\begin{array}{l}\text { Most things people call delinquency don't } \\
\text { really hurt anyone }\end{array}$ & 1.00 & $(0.41)$ & 1.00 & $(0.38)$ \\
\hline I have lots of respect for the police & 1.44 & $(0.46)$ & 1.78 & $(0.53)$ \\
\hline Rules were made to be broken & 2.18 & $(0.71)$ & 2.73 & $(0.79)$ \\
\hline $\begin{array}{l}\text { It's okay to get around the law if you can } \\
\text { get away with it }\end{array}$ & 2.60 & $(0.84)$ & 2.93 & $(0.84)$ \\
\hline
\end{tabular}

We compared models with the loadings constrained to be equal between boys and girls to the model with no equality constraints for each latent variable. None of the change in $\chi^{2}$ tests were significant at the .05 level. The variables that are fixed for scaling have a " 1 " for their factor loading.

Finally, the unconstrained measurement models for theft and violent crime had adequate fits to the data; both had $\chi^{2} / d f$ ratios less than 2, RMSEA less than .05, and NFI over .90; however the $\chi^{2}$ are statistically significant, the ECVI is not over .90 , and the PNFI is low, reflecting large sample size and model complexity (see Model 1 in Table 4 for Theft and Violence).

Despite differences in means between boys and girls on most of the observed variables comprising each of the elements of the social bond, the relationships between the observed variables and the latent constructs were quite similar for boys and girls. In most cases the same observed variables for boys and girls had the highest loadings for each latent variable. This suggested that the observed variables used to capture the latent variables were measuring the same underlying construct for both boys and girls (Table 2).

When we constrained the loadings to be equal between boys and girls, the fit of the models did not get significantly worse (theft model change in $\chi^{2}=13.38$, $d f=12, p>.05$; violent crime model change in $\chi^{2}=16.63, d f=14, p>.05$ ). As indicated by the series of comparisons provided in Table 4 , when the co-variances and the correlated errors, in addition to the loadings, were also restricted to be equal between boys and girls the models were significantly worse. We agree with Byrne (2002) that the equality of measurement loadings is an adequate criterion for concluding that the two measurement models (boys' and girls measurement models) are not significantly different. By this criterion, our analysis indicated the gender did not moderate the measurement of the social bonds we examined. The adequacy of the measurement model and the measurement invariance across boys and girls lays the groundwork for evaluating the invariance of the structural paths. 


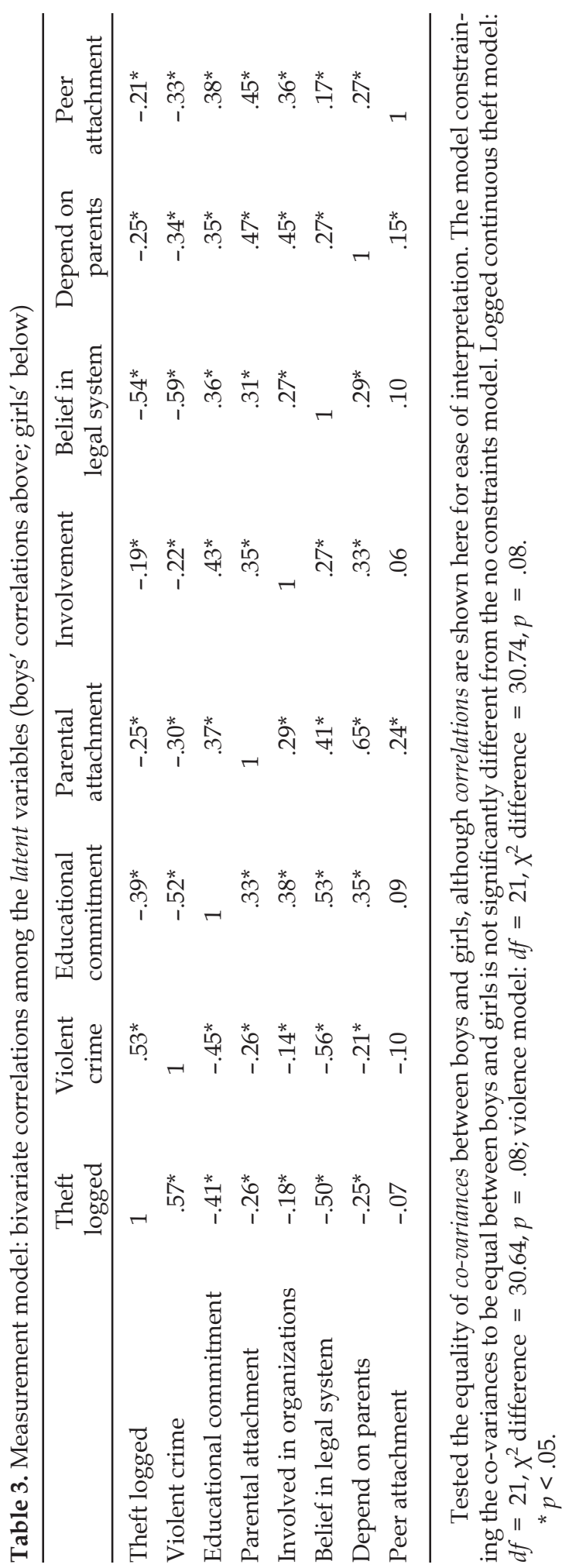




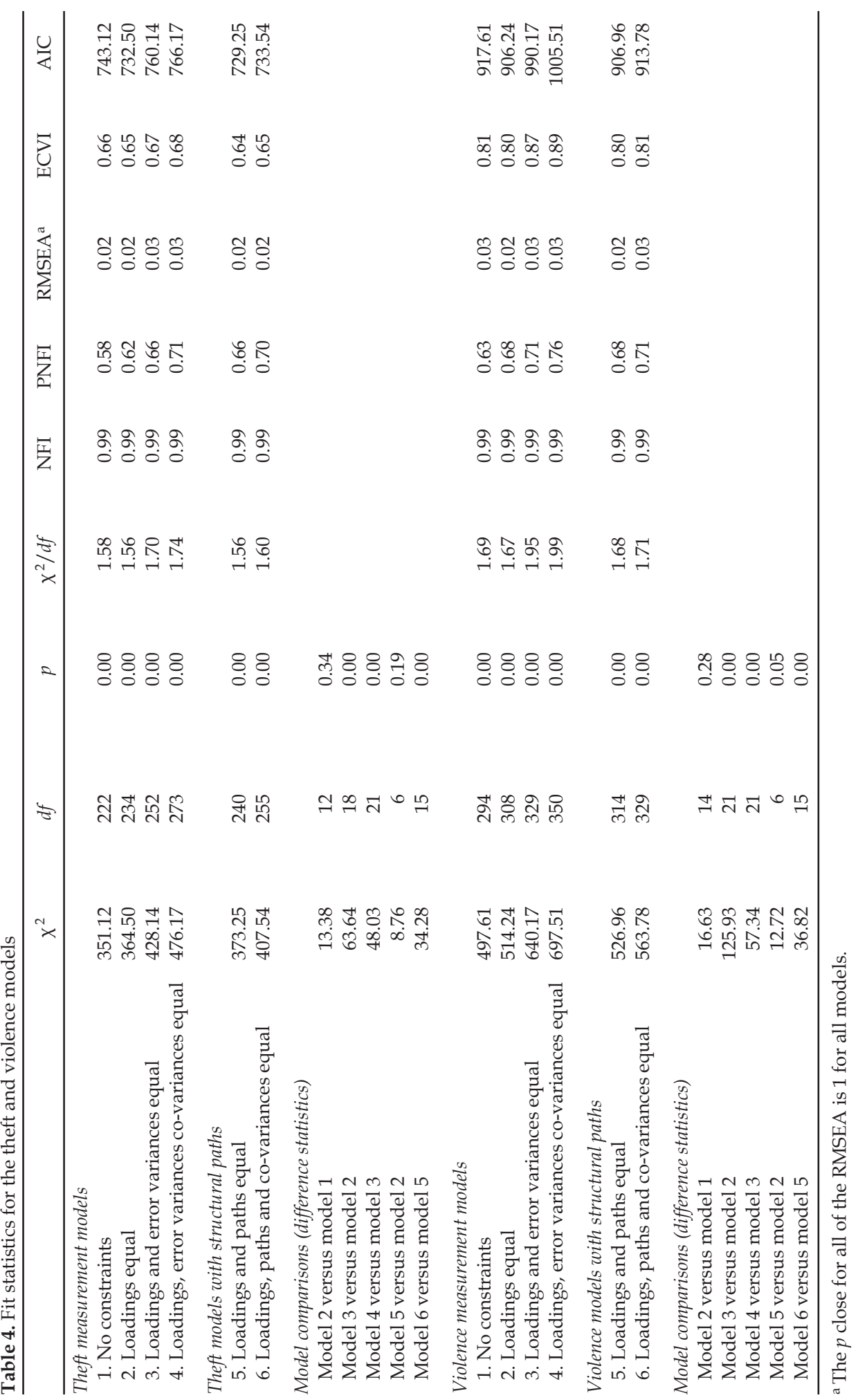




\subsection{Does gender moderate the structural paths between the social bond and delinquency?}

Following Kline (1998) we created a "hybrid" model by turning the co-variances between the exogenous and endogenous variables into structural paths (gammas). From the analysis of the measurement model, we found that the factor loadings for the latent variables did not differ for boys and girls. To evaluate the gender invariance of the structural paths between the social bond and delinquency, we compared a model in which we constrained the factor loadings and structural paths to be equal to a model in which only the factor loadings were equal (results of the measurement model analysis). For the theft structural model, the $p$ value for the change in $\chi^{2}$ is greater than .05 , indicating that gender does not moderate the relationships between elements of the social bond and theft. For theft, neither the factor loadings on the latent variables nor the structural paths between the latent variables and theft differed for boys and girls.

The same is not true for the violence structural model. The $p$ value for the difference in the $x^{2}$ when the structural paths for boys and girls are constrained to be equal is just barely significant ( $p=.048$, rounded to .05 in Table 4$)$. The significant $p$ value suggested that gender moderated (see Table 4, Model 5) the relationship between the structural paths of the social bond and violent delinquency. Yet, when we examined each path individually, none of the individual paths significantly differed by gender according to chi-squared tests for the difference in paths.

The model with both the measurement loadings and the structural paths equal for boys and girls (Model 5 from Table 4) was the best fitting, most parsimonious model for theft and is presented in Figure 1. It was much more difficult to determine the best fitting violent delinquency model, however. While the $\chi^{2}$ was larger for the model in which the loadings and paths were equal compared to the model in which only the loadings were equal (suggesting that the "loadings equal" model is the best fitting), the AIC and the $\chi^{2} / d f$ values were lower for the model in which the loadings and paths were equal, indicating that the more constrained model (identical to the best fitting theft model) had a better fit. Finally, the PNFI and RMSEA values indicated no difference between the "loadings equal" and the "loadings and the paths equal" model. The model with more constraints (i.e., ... the "paths and loadings equal" model) would be the more parsimonious. The overall evidence for a best fitting violence model is mixed. However, we found that we could not reject the $x^{2}$ test of the equality of the structural paths that suggested that the structural paths differed slightly for boys and girls. Because of this evidence, we report in Figure 2 the model in which only the loadings for boys and girls were equal, allowing for different structural path coefficients.

We present the unstandardized path coefficients for each of the social bonds in Figure 1 and Figure 2 with the standardized coefficients in parentheses. Because the boys' and girls' structural models are essentially "the same" for theft we report the findings from one structural model. For the theft model in Figure 1 "beliefs in the legal system" has the strongest significant, negative association with theft, followed by "commitment to education." In Figure 2, the violent delinquency model in which the loadings were equal but the paths were uncon- 


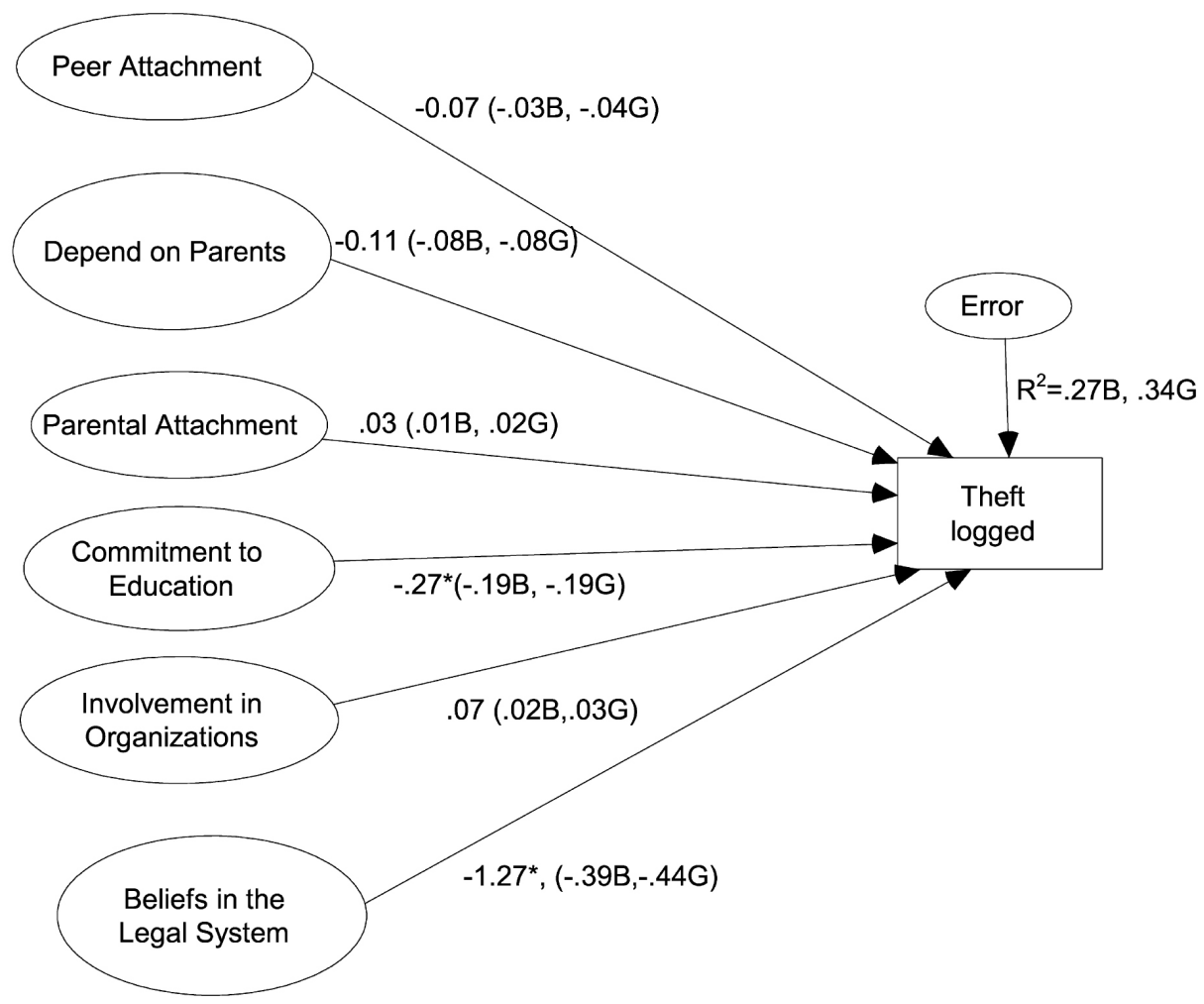

Figure 1. Structural theft model. $c h i^{2}=372.36, d f=239, \mathrm{Cmin} / d f=1.56, p=.00, \mathrm{RMSEA}=.022$, $\mathrm{AIC}=730.36$. Standardized coefficients are included in parentheses. B, boy: G, girl.

strained, we found that both boys and girls, "commitment to education" and "beliefs in the legal system" had significant, negative associations with violent delinquency. However, peer attachment had a significant, negative association with violent delinquency for boys only. This was the only finding that suggests a possible gendered process of social control. This finding is probably surprising to many given a general assumption that girls place a greater stake in caring and empathy in relationships than boys (Gilligan, 1982; Mears et al., 1998). Contrary to this "ethic of care" assumption, we find that for the boys in our sample, peer attachment reduces involvement in violent delinquency.

Our results indicated that for the most part, social bonds operated similarly for boys and girls. We did not find evidence that gender moderated the relationship between the social bond and theft. We found some evidence suggesting that the structural relationship between the social bond and violent delinquency differed for boys and girls. When we treated the structural models between boys and girls as having different structural paths, we found that "commitment" and "belief" were both significantly associated with less violent delinquency, whereas peer attachment was associated with less violent delinquency only for the boys in our sample. Two findings were clear from our results. First, gender did not mod- 


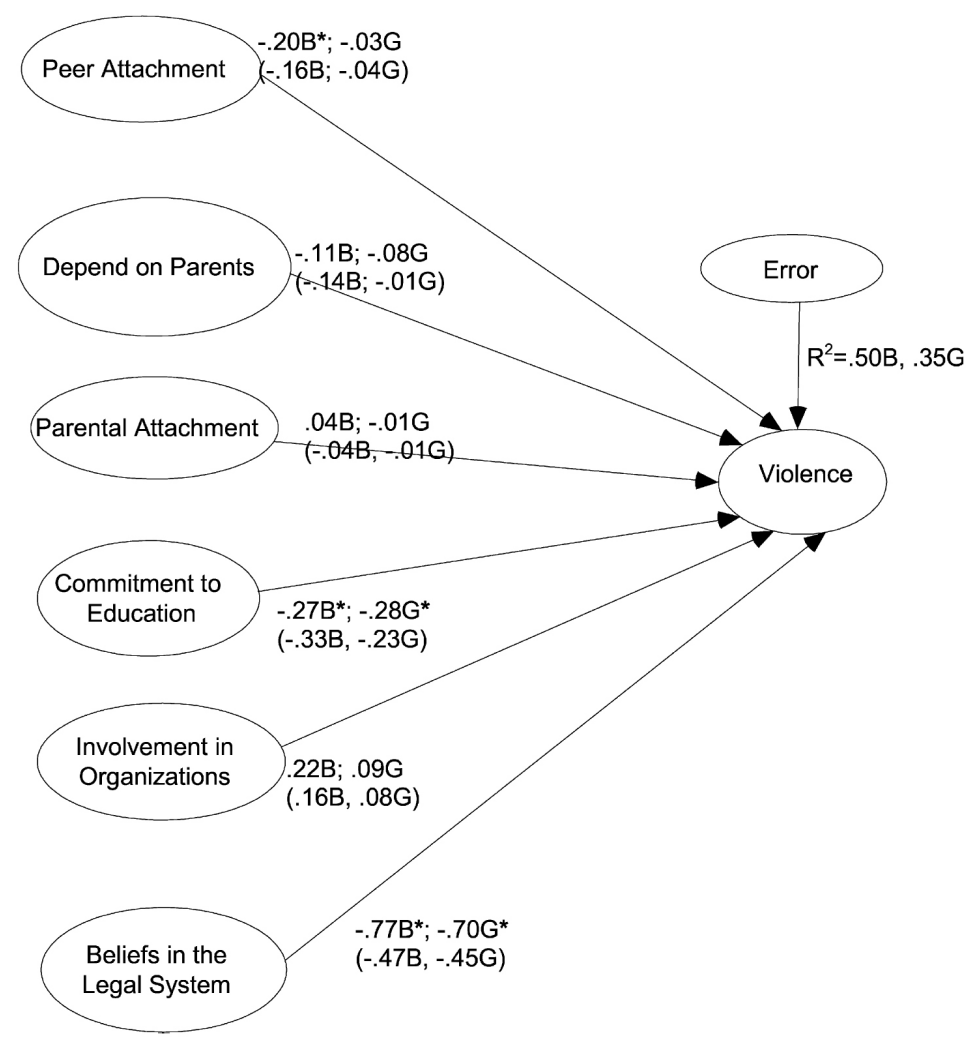

Figure 2. Violence structural model. $\chi^{2}=526.96, d f=314, \mathrm{Cmin} / d f=1.68, p=.00$, RMSEA=.024, $\mathrm{AIC}=906.06$. Standardized coefficients are included in parentheses.

erate the measurement of any aspect of the social bond. We found from our analysis that social bonds should not be measured differently for boys and girls and that boys and girls do not differentially bond to significant others. Second, gender did not moderate the structural relationship between the elements of the social bond and theft. Gender's moderating effect on the structural relationship between the elements of the social bond and violent delinquency was less clear. Our social control model fit the data for boys' violent delinquency better than for girls' violent delinquency and we found one structural path (peer attachment) that was significant only for boys' violent delinquency.

\section{Conclusion}

Researchers interested in explaining gender differences in delinquency often use theories that assume gendered social bonding and control. Much of this work is premised on Hirschi's measurement of the social bond and its inhibitory effect on delinquency. Implicit in this idea of a gendered social bond is the assumption that either the social bond is measured differently for boys and girls or its effects on delinquency are moderated by gender. Our research was designed to test 
this assumption. As we demonstrate, the elements of the social bond are measured similarly for boys and girls. Gender does not moderate the measurement of the social bond or the structural relationships between the elements of the social bond and theft. We have evidence, however, that the structural relationship between the social bond and violent delinquency differs for boys and girls.

We have evidence that suggests that constraining the structural paths to be equal in the violence model does not make the model fit much worse. The constrained model is also the most parsimonious model for boys' and girls' violent delinquency. As with much research in this area, our conclusions are mixed regarding whether gender moderates the relationship between social bonds and violent delinquency. Other researchers have suggested that violent crime is indeed gendered in its prediction (Heimer and DeCoster, 1999; Ogle et al., 1995) and our findings tentatively affirm this.

Multiple-groups structural equation modeling provides a way to specify Hirschi's (1969) theoretical model and to assess whether gender moderates the measurement and modeling of social bonds. Thus, we tested for overall interaction effects and for gender-specific relationships nested within the full model. This type of nuanced analysis is critical to address the debates in contemporary literature regarding gender and criminological theory, specifically theories that utilized concepts of gendered social bonding and control. We generally affirm Hirschi's original hypotheses that increased conventionality is associated with lowered delinquency (theft and violent delinquency), and that the associations between the elements of the social bond and delinquency are similar for boys and girls. One exception exists however, in the unique effect that peer attachment has on boys' violent delinquency. We find that boys who report higher levels of peer attachment, report lower levels of violent delinquency. This finding is echoed in Agnew and Brezina's (1997) work in which they find poor peer relations with peers was positively associated with delinquency for boys. Other research on peer attachment and delinquency in general mirror our findings for boys. Haynie (2001) finds that highly popular respondents, measured as the number of times respondents listed an individual as their "best friend," located in non-delinquent peer groups reported lower levels of delinquency than less popular, or less central youths. Few studies, however, look at gender differences in the impact of the quality of peer ties on delinquency, particularly for violent delinquency. This is an area of fruitful inquiry.

Previous tests of gender and social controls or social bonding were limited by incomplete specifications that omitted elements of the social bond, used only single item indicators of more complex concepts or failed to model the elements of the social bond as latent variables. Additionally, previous tests of the importance of social controls or social bonding for boys' and girls' offending that did not account for possible measurement differences may have attributed gender difference or similarity in social bonds to structural factors rather than measurement factors. Our research suggests that no gendered measurements differences exist for this sample but that structural differences between the elements of the social bond and violent delinquency may need to be addressed. 
We would like to see the findings of our measurement model replicated in other samples that include boys and girls more highly involved in serious delinquency, as the seriousness of delinquency may impact the gender invariance of the social bond as our results tentatively suggest. This is particularly relevant for samples testing the theory for gender differences in violence as girls typically engage in less violence, resulting in girls' models with less variation in the dependent variable which attenuates associations. We would also like to see our measurement model and our gender invariance finding tested in longitudinal research as the delinquency and social bond relationship may be reflexive (Liska and Reed, 1985) and somewhat weaker in longitudinal research (Agnew, 1991). With this reflexive relationship of delinquency and social bonds in mind, it would be interesting to see if deviance is more costly for girls' rather than boys' social bonds during adolescence, suggesting gender variance in the social bond process or equivalent over time, suggesting gender invariance in social control over time-questions only addressed via longitudinal research.

Our findings do not mean that gender is irrelevant for understanding delinquency, but quite the opposite. Gender matters for rates of offending and for the degree of attachment boys and girls experience, as is evident in the means for this sample. Clearly, gender matters in boys and girls rates of offending for many crimes, yet theories of gendered control or bonding may not adequately explain the sex gap in delinquency. Boys and girls are far more similar regarding their social bonds and sensitivity to social control than they are different.

There are many ways in which gender matters in the process leading to delinquency, however. Girls are more likely to suffer from sexual and physical abuse in their families of origin precipitating running away from home and increased exposure to criminal opportunities and particularly, sexual victimization (ChesneyLind and Shelden, 1998; Miller, 1998; Tyler et al., 2001). The experience of sexual abuse may uniquely affect girls' ability to form attachment bonds needed to deter delinquency, or may precipitate involvement as offenders in violence. Additionally, social control via direct control may be gendered, as is suggested by powercontrol theory (Hagan et al., 1987). Omitted from our research is an analysis of parental monitoring and supervision. Gender may moderate the relationship between direct social controls and delinquency as found in past research (Seydlitz, 1991) and needs to be assessed more critically. The differential social location of girls and boys creates different social worlds in childhood and early adolescence. However, it appears that they react similarly to social controls in later adolescence. It is possible that gender-specific theories of deviance are needed when considering adolescent processes outside of the social bond. What is clear is that social bonds are measured similarly for girls and boys and for a given change in social bonds, boys and girls exhibit a similar change in offending. Our findings raise serious questions regarding the gendered nature of social bonding in adolescence and theories of gendered bonding and delinquency. 


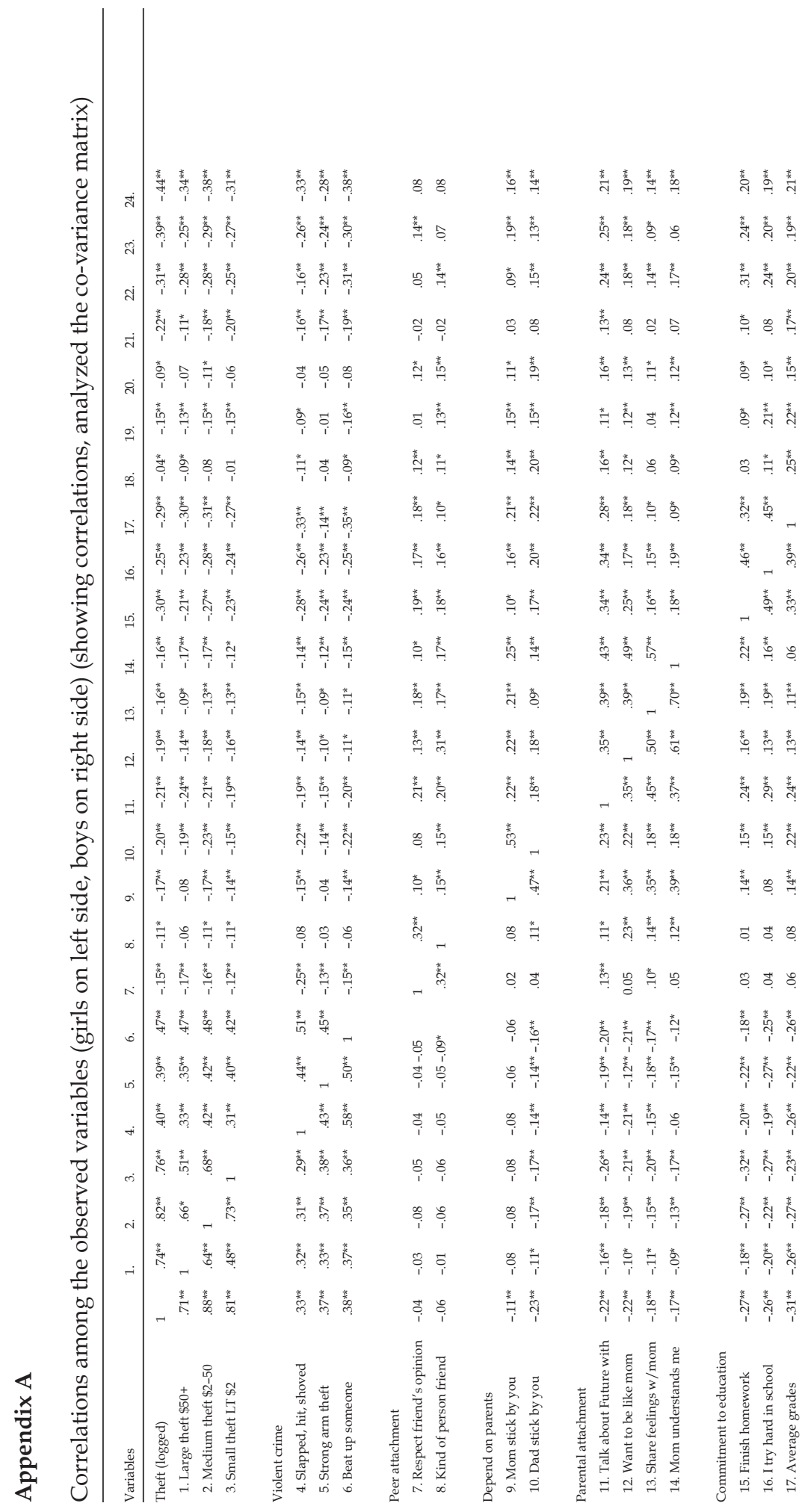




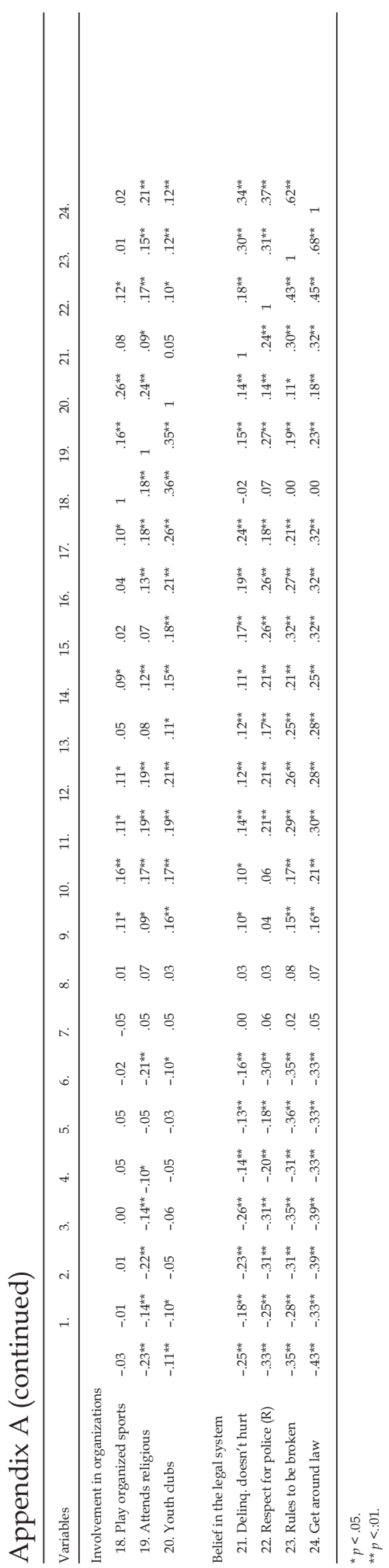




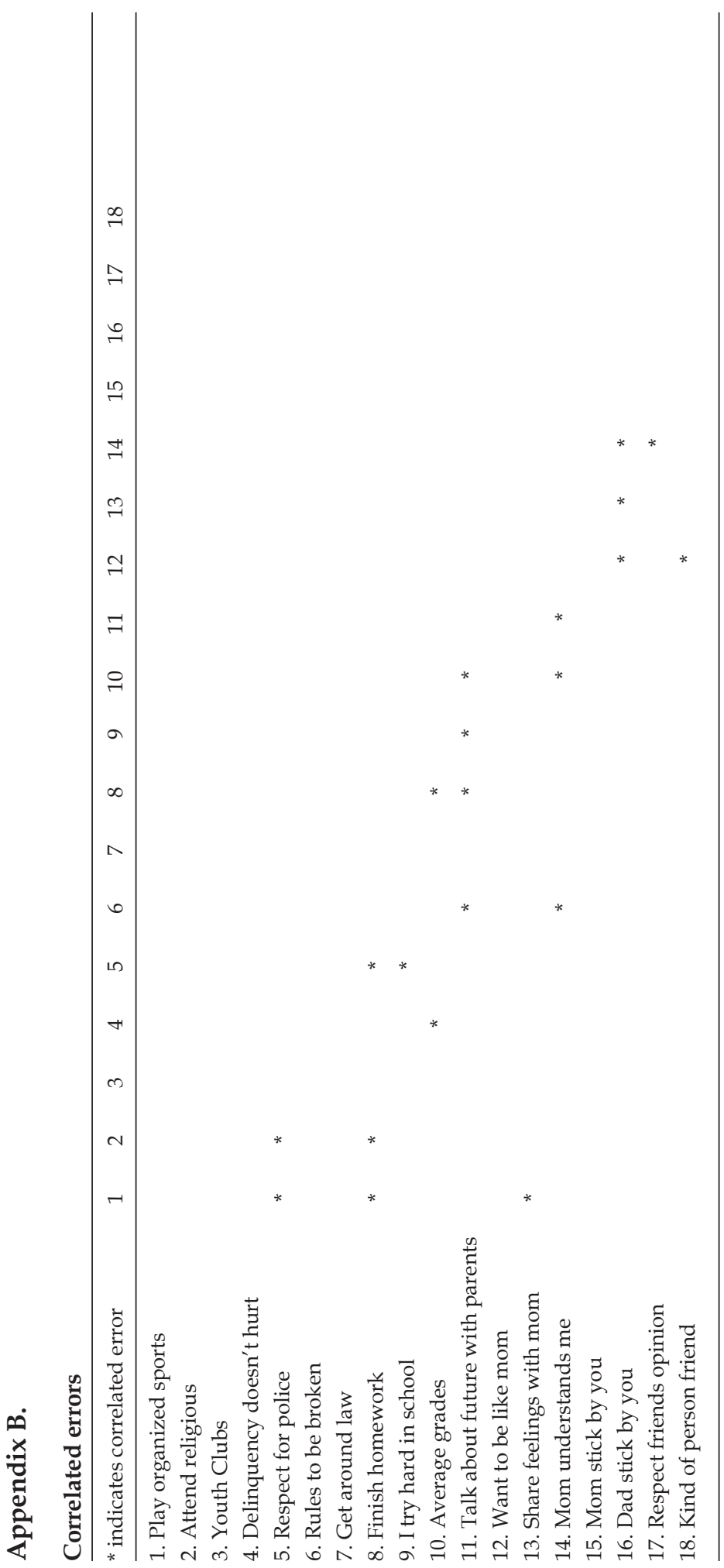




\section{Acknowledgements}

We thank Lynn White, Barbara Costello, James Wright, and the anonymous reviewers for Social Science Research for their helpful comments on the manuscript.

\section{References}

Agnew, R., 1991. A longitudinal test of social control theory and delinquency. Journal of Research in Crime and Delinquency 28, pp. 126-156.

Agnew, R. and Brezina, T., 1997. Relational problems with peers, gender and delinquency. Youth $\mathcal{E}$ Society 29, pp. 84-111.

Alarid, L.F., Burton, V.S. and Cullen, F.T., 2000. Gender and crime among felony offenders: assessing the generality of social control and differential association theories. Journal of Research in Crime and Delinquency 37, pp. 171-199.

Arbuckle, J.L. and Wothke, W., 1999. Amos 4.0 User's Guide. Marketing Department, SPSS Inc.: SmallWaters Corp., Chicago.

Arneklev, B.J., Grasmick, H.G. and Bursik Jr., R.J., 1999. Evaluating the dimensionality and invariance of low self-control. Journal of Quantitative Criminology 15:2, pp. 307-331.

Browne, M.W. and Cudeck, R., 1992. Alternative ways of assessing model fit. Sociological Methods and Research 21:2, pp. 230-258.

Bollen, K., 1989. Structural Equations with Latent Variables. Wiley, New York.

Byrne, B.M., 1988. The self description questionaire: Testing for equivalent validity across ability. Educational and Psychological Measurement 48, pp. 397-406.

Byrne, B.M., 2002. Measurement equivalence: A comparison of methods based on confirmatory factor analysis and item response theory. Journal of Applied Psychology 87:3, pp. 517-529.

Byrne, B.M. and Campbell, T.L., 1999. Cross-cultural comparisons and the presumption of equivalent measurement and theoretical structure: a look beneath the surface. Journal of Cross-cultural Psychology 30:2, pp. 555-574.

Canter, R.J., 1982. Family correlates of male and female delinquency. Criminology 20, pp. 149-167.

Castro, F.G., Maddahian, E., Newcomb, M.D. and Bentler, P.M., 1987. A multivariate model of the determinants of cigarette smoking among adolescents. Journal of Health and Social Behavior 28, pp. 273-289.

Cernkovich, S.A., Giordano, P.C. and Pugh, M.D., 1985. Chronic offenders: the mising cases in self-report delinquency research. Journal of Criminal Law and Criminology 76, pp. 705-732.

Cernkovich, S.A. and Giordano, P.C., 1987. Family relationships and delinquency. Criminology 25, pp. 295-321.

Chesney-Lind, M. and Shelden, R.G, 1998. Girls, delinquency and juvenile justice. Wadsworth, Belmont, CA.

Costello, B.J. and Vowell, P.R., 1999. Testing control theory and differential association: a reanalysis of the richmond youth project data. Criminology 37, pp. 815-842.

Friedman, J. and Rosenbaum, D.P., 1988. Social control theory: the salience of components by age, gender, and type of crime. Journal of Quantitative Criminology 4, pp. 363-381.

Gilligan, C., 1982. In a Different Voice: Psychological Theory and Women's Development. Harvard University Press, Cambridge.

Gottfredson, M.R. and Hirschi, T., 1990. A General Theory of Crime. Stanford University Press, Stanford.

Gottfredson, D.C. and Koper, C.S., 1997. Race and sex differences in the measurement of risk for drug use. Journal of Quantitative Criminology 13:2, pp. 325-347.

Gove, W.R. and Crutchfield, R.D., 1982. The family and juvenile delinquency. The Sociological Quarterly 23, pp. 301-319.

Hagan, J., Gillis, A.R. and Simpson, J., 1987. Class in the household: a power-control theory of delinquency. American Journal of Sociology 92, pp. 788-816.

Hayduk, L.A., 1987. Structural Equation Modeling with LISREL: Essentials and Advances. Johns Hopkins Press, Baltimore.

Haynie, D.L., 2001. Delinquent peers revisted: does network structure matter? American Journal of Sociology 108:4, pp. 1013-1058. 
Heimer, K. and De Coster, S., 1999. The gendering of violent delinquency. Criminology 37, pp. 277-317.

Hindelang, M.J., 1973. Causes of delinquency: a partial replications and extension. Social Problems 20, pp. 471-487.

Hindelang, M.J., Hirschi, T. and Weis, J., 1981. Measuring Delinquency. Sage, Beverly Hills, CA.

Hirschi, T., 1969. Causes of Delinquency. University of California Press, California.

Hoelter, J.W., 1983. The analysis of covariance structures: goodness of fit indices. Sociological Methods Research 11, pp. 325-344.

Huebner, A.J. and Betts, S.C., 2002. Exploring the utility of social control theory for youth development: issues of attachment, involvement and gender. Youth $\mathcal{E}$ Society 34:2, pp. 123-145.

Jaccard, J. and Choi, K.W., 1996. LISREL Approaches to Interaction Effects in Multiple Regression. Sage Publication, Thousand Oaks.

Jensen, G.J. and Eve, R., 1976. Sex differences in delinquency: an examination of popular sociological explanations. Criminology 13, pp. 427-448.

Kempf, K.L., 1993. The empirical status of hirschi's control theory. In: Adler, F., Laufer, W. (Eds.), New Directions in Criminological Theory. pp. 143-160

Kline, R.B., 1998. Principles and Practice of Structural Equation Models. Guildford Press.

Liska, A.E. and Reed, M.D., 1985. Ties to conventional institutions and delinquency: estimating reciprocal effects. American Sociological Review 50, pp. 547-560.

Liu, X. and Kaplan, H.B., 1999. Explaining the gender difference in adolescent delinquent behavior: a longitudinal test of mediating mechanisms. Criminology 37, pp. 195-215.

MaCallum, R.C., Roznowski, M. and Necowitz, L.B., 1992. Model modifications in covariance structure-analysis - The problem of capitalization on chance. Psychological Bulletin 111, pp. 490-504.

Matsueda, R.L., 1982. Testing control theory and differential association: a causal modeling approach. American Sociological Review 47, pp. 489-504.

McCarthy, B., Hagan, J. and Woodward, T.S., 1999. In the company of women: structure and agency in a revised power-control theory of gender and delinquency. Criminology 37, pp. 761-788.

Mears, D.P., Ploeger, M. and Warr, M., 1998. Explaining the gender gap in delinquency: peer influence and moral evaluations of behavior. Journal of Research in Crime and Delinquency 35:3, pp. 251-266.

Miller, J., 1998. Gender and victimization risk among young women in gangs. Journal of Research in Crime and Delinquency 35, pp. 429-543.

Ogle, R.S., Maier-Katkin, D. and Bernard, T.J., 1995. A theory of homicidal behavior among women. Criminology 33, pp. 173-193.

Raju, N.S., Laffitte, L.J. and Byrne, B.M., 2002. Measurement equivalence: a comparison of methods based on confirmatory factor analysis and item response theory. Journal of Applied Psychology 87:2, pp. 517-529.

Reise, S.P., Wildaman, K.F. and Pugh, R.H., 1993. Confirmatory factor analysis and item response theory: two approaches for exploring measurement invariance. Psychological Bulletin 114, pp. 552-566.

Risman, B.J., 1998. Gender Vertigo: American families in Transition. Yale University Press, New Haven.

Seydlitz, R., 1991. The effects of age and gender on parental control and delinquency. Youth and Society 23, pp. 175-201.

Seydlitz, R., 1993. Complexity in the relationships among direct and indirect parental controls and delinquency. Youth and Society 24:3, pp. 243-276.

Smith, D.A. and Paternoster, R., 1987. The gender gap in theories of deviance: issues and evidence. Journal of Research in Crime and Delinquency 24, pp. 140-172.

Steffensmeier, D. and Allan, E., 1996. Gender and crime: toward a gendered theory of female offending. Annual Review of Sociology 22, pp. 459-487.

Tyler, K.A., Hoyt, D., Whitbeck, L. and Cauce, A.M., 2001. The impact of childhood sexual abuse on later sexual victimization among runaway youth. Journal of Research on Adolescence 11, pp. 151-176.

West, C. and Zimmerman, D.H., 1987. Doing gender. Gender and Society 1:2, pp. 125-171.

Worthke, W., 1998. Longitudinal and multi-group modeling with missing data. In: Little, T.D., Schnabel, K.U. and Baumert, J., Editors, 1998. Modeling Longitudinal and Multiple group data: Practical issues, Applied Approaches and Specific Examples. Lawrence Erlbaum Associates, Mahwah, NJ. 